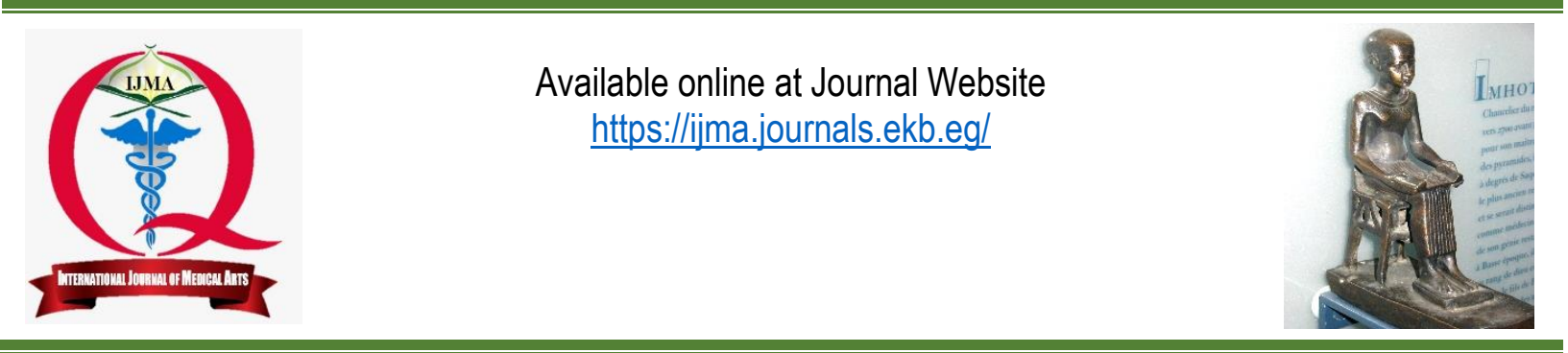

Original article

\title{
Propofol versus Midazolam in Sedation for Upper Gastrointestinal Endoscopy
}

Fouad Ibrahim Mohamed; Yousry Abdelsalam

Department of Anesthesia and Intensive Care, Damietta Faculty of Medicine, Al-Azhar University, Egypt

Corresponding author: Yousry Abdelsalam

Email: yousry.abdelsalam@domazhermedicine.edu.eg

Received at: September 11, Revised at: October 11, 2019;

Accepted at: October 18, 2019; Available online at: October, 18, 2019

\section{Abstract}

Background: Upper gastrointestinal endoscopy [either diagnostic or therapeutic] is widely practiced under conscious sedation. However, the standard sedative agent or drug combination is not yet well established.

Aim of the work: Comparison between propofol-fentanyl and midazolam-fentanyl for sedation in upper gastrointestinal endoscopy.

Patients and methods: Sixty patients from those scheduled to undergo upper gastrointestinal endoscopy at the Gastrointestinal Endoscopy Unit were included. Patients were divided into two equal groups: propofol-fentanyl and midazolam fentanyl. The Anesthetist scheduled to perform the procedures was oriented by the drug, while patients did not know the sedating drug. Prior to the procedure, a clinical history and physical examination was carried out, and throughout the procedure the patient was monitored for blood pressure, heart rate, respiratory rate, and oxygen saturation. Both groups were compared regarding time to recovery, patient satisfaction, physician satisfaction and adverse events.

Results: Recovery time was significantly shorter, patient and physician satisfaction scores were significantly higher among propofol group. On the other side, systolic blood pressure was significantly lower in propofol group at midpoint and recovery times, while oxygen saturation was significantly reduced in midazolam group at intermediate point of the procedure. Finally, hypoxia was significantly higher among midazolam group [reported in $20.0 \%$ ], versus [none] in propofol group. No other adverse events were encountered.

Conclusion: Propofol is better sedative than midazolam for upper gastrointestinal endoscopy. Thus, it should be used as a first-line drug in sedation in our endoscopy units.

Keywords: Endoscopy; Sedation; Fentanyl; Propofol; Midazolam; Gastrointestinal.

This is an open access article under the Creative Commons license [CC BY] [https://creativecommons.org/licenses/by/2.0/]

Please cite this article as: Mohamed Fl, Abdelsalam Y. Propofol versus Midazolam in Sedation for Upper Gastrointestinal Endoscopy. IJMA 2019; 1[2]: 138-143. 


\section{INTRODUCTION}

Upper gastrointestinal endoscopy is a nontraumatic invasive procedure, indicated for diagnosis of upper GI pathology or for the treatment of different $\mathrm{Gl}$ conditions [e.g., hemorrhage, polyps, varices, etc..] [1].

To ensure safe and effective upper $\mathrm{Gl}$ endoscopy, the choice of an appropriate sedative agent is crucial [2]. Sedation goals include keeping patient safe, offer analgesia and amnesia, ensure successful completion of upper GI endoscopy, and fast return of patient to pre-sedative levels ${ }^{[3]}$.

Sedation usually categorized into four stages: minimal, moderate, deep and general anesthesia. The upper gastrointestinal [GI] endoscopy usually performed under moderate sedation [usually described as conscious sedation][4]. A deeper level of sedation than intended level is usually associated with a higher complication rate ${ }^{[5]}$.

Benzodiazepines still the most common sedative agents used for conscious sedation, either solely or in combination with opioids for upper $\mathrm{Gl}$ endoscopy[6].

Midazolam is the most common benzodiazepine used for sedation in upper $\mathrm{Gl}$ endoscopy due to its ability to produce anterograde amnesia and its short half-life. However, it is difficult to maintain stable sedation by the intermittent intravenous [IV] administration of the drug[7]. In addition, fentanyl is the widely used opioid $[8,9]$.

Propofol is a hypnotic drug used for induction of anesthesia with short half-life that permits rapid patient recovery and discharge. Thus, its use is for upper $\mathrm{Gl}$ endoscopy was adopted in many endoscopy centers[10]. But, it is associated with deep sedation[11,12], and many side effects were reported when used alone for sedation. The most critical are apnea, hypoxia and cardiovascular complications ${ }^{[13]}$. These side effects seem to be related to the dose and speed of injection[14].

\section{AIM OF THE WORK}

We intended to use propofol-fentanyl or midazolam-fentanyl for sedation in upper $\mathrm{GI}$ endoscopy, to establish a safe and effective combination for sedation.

\section{PATIENTS AND METHODS}

This was a prospective, single-blind, randomized controlled trial, which carried out between January 2015 and October 2017 at the Gastrointestinal Endoscopy Clinic of the Department of Gastroenterology at Damietta University Hospital [Al-Azhar University]. We recruited 60 patients from those scheduled to undergo upper gastrointestinal endoscopy at the Gastrointestinal Endoscopy Unit. The inclusion criteria were age > 18 years, physical status classified as ASA I or II. The exclusion criteria were: pregnancy, a history of allergy to the medications to be administered, a history of allergy to soy beans or eggs, a psychotic disorder; being under treatment with psychoactive medications or a heavy consumer of alcohol, Child-Pugh class $\mathrm{C}$ cirrhosis, presence of chronic kidney disease [being on dialysis]; and being submitted to endoscopy as an emergency procedure. Patients were divided into two groups of 30 patients: propofol-fentanyl and other 30 patients, midazolam fentanyl. The Anesthetist scheduled to perform the procedures was oriented by the drug, while patients did not know the sedating drug.

Drug infusion was performed by the nursing staff and attending anesthetist. In both groups, the objective was to achieve conscious sedation by using the dose calculated for that purpose. The propofol and midazolam were administered by intravenous bolus and supplemented as necessary by the anesthetist to maintain the desired level of sedation. A single dose of fentanyl was used in both groups. The fixed maximum dose for midazolam was $10 \mathrm{mg}$ or $0.1 \mathrm{mg} / \mathrm{kg}$ of body weight. If additional sedation became necessary, the anesthetist had the option of suspending the initial regimen and adding propofol.

In midazolam fentanyl [MF] group, the initial dose of midazolam was $3-5 \mathrm{mg}$, and the maintenance dose was 0.5 to $1 \mathrm{mg}$ every $2-3$ minutes up to a maximum cumulative dose of $10 \mathrm{mg}$ or $0.1 \mathrm{mg} / \mathrm{kg}$ of body weight. The dose of fentanyl was $50 \mu \mathrm{g}$ single dose. In propofol-fentanyl group [PF], the initial dose of propofol was $0.5 \mathrm{mg} / \mathrm{kg}$; the maintenance dose was $10-20 \mathrm{mg}$ bolus at $60 \mathrm{~s}$ intervals. The dose of fentanyl was $50 \mu \mathrm{g}$ single dose, as in MF group. 
Prior to the procedure, a clinical history and physical examination was carried out for each patient. The anesthetic risk was assessed with the ASA classification of physical status, and the patients completed a demographic questionnaire. Continuous monitoring during the procedure included the noninvasive measurement of blood pressure, heart rate, respiratory rate, and oxygen saturation. We defined the following evaluation time points: "Baseline" [immediately before the procedure]; "duodenum" [the approximate midpoint of the procedure, when the endoscopist was evaluating the duodenum or the jejunal loop in postgastrectomy Patients]; and "recovery" [when the patient was awake and underwent the final evaluation].

During the procedure, the level of sedation was evaluated. We applied the Observer's Assessment of Alertness/Sedation [OAA/S] scale, which is scored as [1 point, awake; 2 points, somnolent/drowsy; 3 points, responsive to loud or repeated verbal stimuli; 4 points, responsive to physical/painful stimuli; and 5 , no response to physical/painful stimuli]. The OAA/S scale is determined simultaneously every 2 min. An independent observer was responsible for the monitoring, which included evaluating the level of consciousness, readout of other vital signs, collection of data regarding drugs and doses used, use of benzodiazepine or opioid antagonists, and occurrence of cardiorespiratory events, such as hypoxemia [defined as $\mathrm{SpO}_{2}<90 \%$ for $>30$ s after application of the jaw thrust maneuver], hypotension [defined as $\geq 20 \%$ decrease in systolic or diastolic blood pressure], and bradycardia [heart rate $<50 \mathrm{bpm}]$.

Hypoxemia was classified as mild if it responded to supplemental oxygen delivered at 3-4 L/min; severe if it did not respond to supplemental oxygen and the patient required noninvasive ventilatory support [e.g., bag-mask ventilation] or intubation. We compared the two groups in terms of the time to induction [interval between the first drug bolus administration and initiation of the procedure], time to recovery [interval between removal of the endoscope and final evaluation], and time to discharge [interval between removal of the endoscope and departure from the endoscopy unit]. The final evaluation began when the bispectral index [BIS] monitor indicated at least 90. Patients were discharged only when they had achieved an OAA/S score of 5 [the maximum], a BIS > 90 , and reported no pain or any other types of discomfort.

At discharge, patient satisfaction was assessed with a 10-point visual analog scale [1 = least satisfied and $10=$ most satisfied]. The patients also completed a satisfaction questionnaire before leaving the facility. The visual analog scale was also applied to the endoscopists who performed the procedures to assess their level of satisfaction with the sedation regimen and was scored as follows: 1$3=$ considerable difficulty in performing the procedure; 4-7 = minor difficulty in performing the procedure [patient moved at the beginning or end of the procedure]; and $8-10=$ no difficulty in performing the procedure.

Data analysis: data were collected on preprepared excel sheet, then coded and transferred to statistical package of social science [SPSS] program for statistical analysis. Quantitative data were expressed as arithmetic mean and standard deviation. On the other side, qualitative data were expressed as frequency [number] and percentages. Both groups were compared by independent sample's student [t] test or Chi square test when appropriate, and $p$ value $<0.05$ was considered significant.

\section{RESULTS}

Patient age ranged from 29 to 61 years, with no significant difference between propofol and midazolam groups. In addition, $66.7 \%$ of propofol groups were males, compared to $56.7 \%$ in midazolam group. All patients were ASA class I or II with no significant difference between groups [ASA-I represented $73.3 \%$ and $66.7 \%$ of propofol and midazolam groups respectively]. Furthermore, patients in both groups were comparable as regard to patient weight, height, body mass index, and serum levels of albumin, total bilirubin, aspartate transaminase [AST], alanine transaminase [ALT], international normalized ratio [INR] and creatinine [Table 1].

Outcome among studied patients were presented in details in table [2]. Briefly, both propofol and midazolam groups were comparable as regard to endoscopy time, basal systolic blood pressure, basal oxygen saturation, heart rate and 
OAA/S throughout the whole procedure. However, recovery time was significantly shorter in propofol group. In addition both patient and physician satisfaction scores were significantly higher among propofol group. On the other side, systolic blood pressure was significantly reduced in propofol group at midpoint and recovery times, while oxygen saturation was significantly reduced in midazolam group at intermediate point of the procedure. Finally, hypoxic events were significantly higher among midazolam group [reported in 20.0\%], versus [none] in propofol group [table 2]. No hypotension or bradycardia was reported in any patients in both groups.

Table [1]: Characters of studied patient

\begin{tabular}{|c|c|c|c|c|c|}
\hline \multicolumn{2}{|c|}{ Variable } & Propofol & Midazolam & Test & $P$ \\
\hline \multicolumn{2}{|c|}{ Age [years] } & $\begin{array}{c}51.57 \pm 4.69 \\
39-58\end{array}$ & $\begin{array}{c}51.40 \pm 7.08 \\
29-61\end{array}$ & 0.11 & 0.91 \\
\hline \multirow[t]{2}{*}{ Sex } & Male & $20[66.7 \%]$ & $17[56.7 \%]$ & \multirow{2}{*}{0.63} & \multirow{2}{*}{0.42} \\
\hline & Female & $10[33.3 \%]$ & $13[43.3 \%]$ & & \\
\hline \multirow{2}{*}{$\begin{array}{l}\text { ASA } \\
\text { Class }\end{array}$} & 1 & $22[73.3 \%]$ & $20[66.7 \%]$ & \multirow{2}{*}{0.31} & \multirow{2}{*}{0.57} \\
\hline & $\|$ & $8[26.7 \%]$ & $10[33.3 \%]$ & & \\
\hline \multicolumn{2}{|c|}{ Weight [kg] } & $74.50 \pm 4.31$ & $73.83 \pm 4.54$ & 0.58 & 0.56 \\
\hline \multicolumn{2}{|c|}{ Height [m] } & $1.69 \pm 0.03$ & $1.68 \pm 0.04$ & 0.60 & 0.55 \\
\hline \multicolumn{2}{|c|}{ BMl } & $26.18 \pm 0.68$ & $26.11 \pm 0.66$ & 0.41 & 0.68 \\
\hline \multicolumn{2}{|c|}{ Albumin } & $3.93 \pm 0.24$ & $3.93 \pm 0.27$ & 0.05 & 0.96 \\
\hline \multicolumn{2}{|c|}{ Bilirubin } & $1.11 \pm 0.26$ & $1.08 \pm 0.22$ & 0.37 & 0.71 \\
\hline \multicolumn{2}{|c|}{ AST } & $23.73 \pm 6.44$ & $24.73 \pm 8.28$ & 0.52 & 0.60 \\
\hline \multicolumn{2}{|c|}{ ALT } & $29.03 \pm 5.51$ & $28.63 \pm 7.70$ & 0.23 & 0.82 \\
\hline \multicolumn{2}{|c|}{ INR } & $1.13 \pm 0.11$ & $1.13 \pm 0.10$ & 0.24 & 0.80 \\
\hline \multicolumn{2}{|c|}{ Creatinine } & $0.81 \pm 0.18$ & $0.84 \pm 0.13$ & 0.81 & 0.41 \\
\hline
\end{tabular}

ASA: American society for anesthesiologists

Table [2]: Outcome among studied patients

\begin{tabular}{|c|c|c|c|c|c|}
\hline & & Propofol & Midazolam & Test & $P$ \\
\hline \multicolumn{2}{|c|}{ Endoscopy time [min] } & $30.27 \pm 3.70$ & $31.90 \pm 4.63$ & 1.51 & 0.13 \\
\hline \multicolumn{2}{|c|}{ Recovery time } & $7.53 \pm 2.78$ & $29.47 \pm 4.45$ & 22.91 & $<0.001^{*}$ \\
\hline \multicolumn{2}{|c|}{ Patient satisfaction score } & $8.93 \pm 0.78$ & $8.23 \pm 0.82$ & 3.38 & $0.001^{*}$ \\
\hline \multicolumn{2}{|c|}{ Physician satisfaction score } & $8.70 \pm 1.37$ & $6.67 \pm 1.81$ & 4.91 & $<0.001^{*}$ \\
\hline \multirow[t]{4}{*}{ SBP } & Basal & $132.83 \pm 8.38$ & $130.17 \pm 8.46$ & 1.22 & 0.23 \\
\hline & Duodenum & $119.50 \pm 8.44$ & $126.00 \pm 7.00$ & 3.24 & $0.002^{*}$ \\
\hline & Recovery & $113.67 \pm 7.76$ & $122.00 \pm 7.02$ & 4.36 & $<0.001^{*}$ \\
\hline & Change & $19.17 \pm 4.75$ & $8.17 \pm 3.59$ & 10.12 & $<0.001^{*}$ \\
\hline \multirow[t]{4}{*}{$\mathrm{SPO}_{2}$} & Basal & $97.63 \pm 0.81$ & $97.70 \pm 0.65$ & 0.35 & 0.72 \\
\hline & Duodenum & $96.67 \pm 1.03$ & $94.90 \pm 3.39$ & 2.73 & $0.008^{*}$ \\
\hline & Recovery & $96.73 \pm 0.91$ & $96.13 \pm 1.85$ & 1.59 & 0.12 \\
\hline & Change & $0.93 \pm 0.94$ & $1.63 \pm 1.90$ & 1.80 & 0.08 \\
\hline \multirow[t]{4}{*}{$\mathrm{HR}$} & Basal & $72.40 \pm 1.59$ & $72.17 \pm 1.70$ & 0.54 & 0.58 \\
\hline & Duodenum & $71.53 \pm 1.43$ & $71.53 \pm 1.46$ & 0.01 & 0.99 \\
\hline & Recovery & $70.27 \pm 1.20$ & $70.37 \pm 1.33$ & 0.31 & 0.76 \\
\hline & Change & $2.13 \pm 1.20$ & $1.80 \pm 0.89$ & 1.23 & 0.22 \\
\hline \multirow[t]{3}{*}{$\mathrm{OAA} / \mathrm{S}$} & Basal & $3.87 \pm 0.43$ & $3.80 \pm 0.41$ & 0.61 & 0.45 \\
\hline & Duodenum & $4.40 \pm 0.50$ & $4.53 \pm 0.51$ & 1.03 & 0.31 \\
\hline & Recovery & $2.83 \pm 0.59$ & $2.80 \pm 0.55$ & 0.22 & 0.88 \\
\hline \multirow[t]{2}{*}{ Hypoxia } & Yes & $0[0.0 \%]$ & $6[20.0 \%]$ & \multirow{2}{*}{6.67} & \multirow{2}{*}{$0.010^{*}$} \\
\hline & No & $30[100.0 \%]$ & $24[80.0 \%]$ & & \\
\hline
\end{tabular}

SBP: Systolic blood pressure; $\mathrm{SPO}_{2}$ : oxygen saturation; HR: heart rate; OAA/S: The Observer's Assessment of Alertness/Sedation

\section{DISCUSSION}

Many drugs [benzodiazepines, narcotics, propofol, tranquilizers, antihistamines, and dopaminergic receptor antagonists] were used for conscious [moderate] sedation for upper gastrointestinal endoscopy. Drug combination between midazolam [short-acting benzodiazepine] and a narcotic [e.g., pethidine] used for sedation in about three fourths of upper GIT endoscopy and propofol alone used in one fourth[15]. 
Each drug or drug combination had its safety and efficacy profile. Thus, the search for the most effective and safe drug or drug combination is continued. Here we studied propofol-fentanyl versus midazolam-fentanyl, and results of the present study revealed that, propofol is more effective and safe than midazolam, when combined with fentanyl for sedation in upper GI endoscopy.

Different authors supports the superiority of propofol as it provides stable sedation all-over the procedure and reported that, patients did not complain of any restlessness [16-18].

In addition, the advantages of propofol included rapid onset of action and short duration which allow rapid recovery. Thus, propofol could be continuously administered, ensuring the constant depth of sedation. On the other side, propofol had a narrow safety range, which could result in depression of cardiovascular function with increased dose. Combination with synergistic agents permits dose reduction of propofol, decreasing liability for cardiovascular dysfunction and maintains the depth of sedation[7]. Wang et al.[19] advocated propofol for upper $\mathrm{GI}$ endoscopy as it was safe and effective in healthy and cirrhotic patients. In addition, it had shorter recovery and rapid discharge, better sedation, and greater patient satisfaction than midazolam, without cardiopulmonary adverse events. Also, Poulos et al.[20] recommended that, propofol should be used as the standard pre-endoscopy agent for sedation [even in cirrhotic patient] as it is associated with quicker recover than midazolam based sedation regiments. They added, propofol is associated with greater patient satisfaction, reduced pain during procedure. Furthermore, Correia et al. [21] reported results in concordance with results of the present work. Moreover, Martinez et al.[22] reported that, continuous propofol sedation in geriatrics [patients $>80$ years] is generally as safe as in younger populations, although, geriatrics are more prone to complications. Singh et al.[23] conducted a metaanalysis of 20 studies for sedation in cirrhotic patients and showed that, recovery time was shorter with propofol use than midazolam. In addition, propofol use was associated with marked patient satisfaction with the use of propofol, although the endoscopy time was comparable between both drugs.

Results of the present work are in agreement with Watanabe et al. ${ }^{[7]}$ who reported that, physician satisfaction score was significantly higher with propofol sedation due to decreased patients movements during the procedure when compared to midazolam group. This reduction of patient's movements leads to reduction of operator stress.

In conclusion, propofol is significantly better than midazolam for sedation in upper $\mathrm{Gl}$ endoscopy. Thus, it is advocated to use propofol as a firstchoice in sedation in our endoscopy units.

\section{REFERENCES}

1. Ristikankare $M$, Julkunen $R$, Heikkinen M, Mattila M, Laitinen T, Wang SX, Hartikainen J. Sedation, topical pharyngeal anesthesia and cardiorespiratory safety during gastroscopy. J Clin Gastroenterol. 2006; 40:899-905. [DOI:10.1097/01.mcg. 0000225579. 65761.b1]

2. Shin S, Lee SK, Min KT, Kim HJ, Park CH, Yoo YC. Sedation for interventional gastrointestinal endoscopic procedures: are we overlooking the "pain"? Surg Endosc. 2014; 28:100-7. [DOI:10.1007/ s00464-013-3133-y]

3. Narula N, Masood S, Shojaee S, McGuinness B, Sabeti S, Buchan A. Safety of Propofol versus NonpropofolBased Sedation in Children Undergoing Gastrointestinal Endoscopy: A Systematic Review and Meta-Analysis. Gastroenterol Res Pract. 2018, Article ID 6501215, 11 pages [DOI:10.1155/ 2018/6501215]

4. Thuluvath PJ. Toward safer sedation in patients with cirrhosis; have we done enough? Gastrointest Endosc. 2009; 70: 269-70. [DOl:10.1016/ j.gie.2009.01.029].

5. Cohen LB. Patient monitoring during gastrointestinal endoscopy: why, when, and how? Gastrointest Endosc Clin N Am. 2008; 18: 651-63, vii [DOI: 10.1016/j.giec.2008.06.015]

6. Wahab EA, Hamed EF, Ahmad HS, Abdel Monem SM, Fathy T. Conscious sedation using propofol versus midazolam in cirrhotic patients during upper $\mathrm{Gl}$ endoscopy: A comparative study. JGH Open 2019; 3[1]: 25-31. [DOI:10.1002/jgh3.12098]

7. Watanabe K, Hikichi T, Takagi T, Suzuki R, Nakamura J, Sugimoto M, et al. Propofol is a more effective and safer sedative agent than midazolam in endoscopic injection sclerotherapy for esophageal varices in patients with liver cirrhosis: a randomized controlled 
trial. Fukushima J Med Sci. 2018; 64 [3]: 133-141. [DOI:10.5387/fms.2018-21]

8. Thomson A, Andrew G, Jones DB. Optimal sedation for gastrointestinal endoscopy: review and recommendations. J Gastroenterol Hepatol. 2010; 25: 469-478 [DOI: 10.1111/ j.1440-1746.2009.06174.x]

9. Benson AA, Cohen LB, Waye JD, Akhavan A, Aisenberg J. Endoscopic sedation in developing and developed countries. Gut Liver 2008; 2: 105-112 [DOI: 10.5009/ gnl.2008.2.2.105]

10. Fanti L, Testoni PA. Sedation and analgesia in gastrointestinal endoscopy: what's new? World J Gastroenterol. 2010; 16: 2451-2457 [DOI: 10.3748/ wjg.v16.i20.2451]

11. Lichtenstein DR, Jagannath S, Baron TH, Anderson MA, Banerjee S, Dominitz JA, et al. Sedation and anesthesia in $\mathrm{Gl}$ endoscopy. Gastrointest Endosc. 2008; 68: 815-826 [DOI: 10.1016/j.gie.2008.09.029]

12. Dumonceau JM, Riphaus A, Aparicio JR, Beilenhoff U, Knape JT, Ortmann M, et al. European Society of Gastrointestinal Endoscopy, European Society of Gastroenterology and Endoscopy Nurses and Associates, and the European Society of Anaesthesiology Guideline: Non-anesthesiologist administration of propofol for $\mathrm{Gl}$ endoscopy. Endoscopy 2010; 42: 960-974 [DOI: 10.1055/s-00301255728]

13. Park CH, Park SW, Hyun B, Lee J, Kae SH, Jang HJ, Koh DH, Choi MH. Efficacy and safety of etomidatebased sedation compared with propofol-based sedation during ERCP in low risk patients: a doubleblind, randomized, noninferiority trial. Gastrointest Endosc. 2018; 87:174-84. [DOI:10.1016/ j.gie. 2017.05.050]

14. Chen L, Liang X, Tan X, Wen H, Jiang J, Li Y. Safety and efficacy of combined use of propofol and etomidate for sedation during gastroscopy. Systematic review and meta-analysis. Medicine 2019; 98:20[e15712].[DOI:10.1097/MD.000000000001571]

15. Cohen L, Wecsler J, Gaetano J, Benson AA, Miller KM, Durkalski V, Aisenberg J. Endoscopic sedation in the United States; results from a nationwide survey. Am J Gastroenterol. 2006; 101: 967-74. [DOl: 10.1111/j.1572-0241.2006.00500.x].
16. Wadhwa V, Issa D, Garg S, Lopez R, Sanaka MR, Vargo JJ.. Similar risk of cardiopulmonary adverse events between propofol and traditional anesthesia for gastrointestinal endoscopy: A systematic review and meta-analysis. Clin Gastroenterol Hepatol. 2017; 15: 194-206. [DOI:10.1016/j.cgh.2016.07.013].

17. Yamaguchi D, Yamaguchi N, Takeuchi Y, Yukimoto T, Ikeda K, Matsumoto K, et al. Comparison of sedation between the endoscopy room and operation room during endoscopic submucosal dissection for neoplasms in the upper gastrointestinal tract. BMC Gastroenterol. 2017; 17: 127. [DOl:10.1186/s12876017-0692-8]

18. Ominami M, Nagami Y, Shiba M, Tominaga K, Sakai T, Maruyama $\mathrm{H}$, et al. Comparison of propofol with midazolam in endoscopic submucosal dissection for esophageal squamous cell carcinoma: A randomized controlled trial. J Gastroenterol. 2018; 53: 397-406. [DOI:10.1007/s00535-017-1358-6].

19. Wang D, Chen C, Chen J, Xu Y, Wang L, Zhu Z, et al. The use of propofol as a sedative agent in gastrointestinal endoscopy; a meta-analysis. PLoS One. 2013; 8[1]: e53311. [DOI:10.1371/journal. pone.0053311].

20. Poulos JE, Kalogerinis PT, Caudle JN. Propofol compared with combination propofol or midazolam/ fentanyl for endoscopy in a community setting. AANA J. 2013; 81: 31-6. [PMID: 23513321].

21. Correia LM, Bonilha DQ, Gomes GF, Brito JR, Nakao FS, Lenz L, et al. Sedation during upper GI endoscopy in cirrhotic outpatients; a randomized, controlled trial comparing propofol and fentanyl with midazolam and fentanyl. Gastrointest Endosc. 2011; 73[1]: 45-51. [DOI:10.1016/j.gie.2010.09.025]

22. Martinez JF, Aparicio JR, Company L, Ruiz F, GómezEscolar L, Mozas I, Casellas JA. Safety of continuous propofol sedation for endoscopic procedures in elderly patients. Rev Esp Enferm Dig. 2011; 103: 76-82. [DOI:10.4321/s113001082011000200005].

23. Singh H, Poluha W, Cheung M, Choptain N, Baron KI, Taback SP. Propofol for sedation during gastrointestinal endoscopy. Cochrane Database Syst. Rev. 2008; 4: CD006268. [DOI:10.1002/ 14651858. CD006268.pub2]. 